\title{
Erratum to: Measuring insulin adherence among adults with type 2 diabetes
}

\author{
Chandra Y. Osborn ${ }^{1} \cdot$ Jeffrey S. Gonzalez ${ }^{2,3}$
}

Published online: June 29, 2016

(c) Springer Science+Business Media New York 2016

\section{Erratum to: J Behav Med DOI 10.1007/s10865-016-9741-y}

The original version of this article unfortunately contained a mistake. The spelling of the second author's name was incorrect. The correct spelling is Jeffrey S. Gonzalez.

The online version of the original article can be found under doi:10. 1007/s10865-016-9741-y.

Chandra Y. Osborn

chandra.osborn@vanderbilt.edu

1 Department of Medicine, Department of Biomedical Informatics, Center for Health and Health Education, Vanderbilt University Medical Center, 2525 West End Ave. Suite 370, Nashville, TN 37203, USA

2 Ferkauf Graduate School of Psychology, Yeshiva University, New York, NY, USA

3 Diabetes Research Center, Albert Einstein College of Medicine, New York, NY, USA 